\title{
Is obesity a risk factor for low back pain? An example of using the evidence to answer a clinical question Timothy A Mirtz* and Leon Greene
}

\author{
Address: University of Kansas, Department of Health, Sport, and Exercise Science. Lawrence, Kansas, USA \\ Email: Timothy A Mirtz* - numitor@ku.edu; Leon Greene - jlg@ku.edu \\ * Corresponding author
}

Published: II April 2005

Chiropractic \& Osteopathy 2005, I3:2 doi:10.1 | 86/1746-1340-13-2

This article is available from: http://www.chiroandosteo.com/content//3/I/2

(c) 2005 Mirtz and Greene; licensee BioMed Central Ltd.

This is an Open Access article distributed under the terms of the Creative Commons Attribution License (http://creativecommons.org/licenses/by/2.0), which permits unrestricted use, distribution, and reproduction in any medium, provided the original work is properly cited.
Received: 07 April 2005

Accepted: II April 2005

\begin{abstract}
Background: Obesity as a causal factor for low back pain has been controversial with no definitive answer to this date. The objective of this study was to determine whether obesity is associated with low back pain. In addition this paper aims to provide a step-by-step guide for chiropractors and osteopaths on how to ask and answer a clinical question using the literature.

Methods: A literature review using the MEDLINE search engine using the keywords "obesity", "low back pain", "body mass index" "BMI" and "osteoarthritis" from years 1990 to 2004 was utilised. The method employed is similar to that utilised by evidence-based practice advocates.

Results: The available data at this time is controversial with no clear-cut evidence connecting low back pain with obesity.

Conclusion: There is a lack of a clear dose-response relationship between body mass index (BMI) and low back pain. Further, studies on the relationship between obesity and related lumbar osteoarthritis, knee pain, and disc herniation are also problematic. There is little doubt that future studies with controlled variables are needed to determine the existence of an unambiguous link, if any.
\end{abstract}

\section{Introduction}

Obesity is a problem of epidemic proportion [1,2] Despite record rates of non-physician supervised dieting and the availability of numerous weight loss programs, the problem is not abating [3]. Complicating this, is that most primary care physicians do not treat obesity, citing a lack of time, resources, insurance reimbursement, and knowledge of effective interventions as significant barriers [4]. Musculoskeletal disorders including low back pain (LBP) represent a considerable public health problem and a common diagnosis creating absenteeism and the need for disability pensions [5]. It is estimated that about $80 \%$ of the United States and Canadian population will experience LBP during adulthood [6]. Most low back pain is selflimiting and will ultimately resolve in two weeks $(50 \%$ of those affected) to six weeks ( $90 \%$ of those affected), however it remains an intriguing clinical problem [6].

It is widely noted that the economic cost of obesity and its related disorders are staggering, with lifestyle related conditions such as diabetes mellitus and coronary heart disease placing a large economic burden on the health care 
system [1-4]. However, low back pain also has a significant socioeconomic impact. Cost estimates range from US $\$ 20$ billion to $\$ 50$ billion annually, with $10 \%$ of the patients accounting for 85 to $90 \%$ of the costs [6]. In Australia, Walker et al estimated the cost of low back pain in 2001 alone to be AUD $\$ 9.17$ billion [7].

One question, which arises from the discussion concerning obesity, is whether obesity is a risk factor for low back pain. "Buckwalter et al contended that a number of medical conditions including obesity, along with diabetes and hypertension, may influence the pathophysiology of diseases of the tendons and ligaments during the process of aging thus potentially leading to low back pain [8]. Along with low back pain, the conventional wisdom is that overweight persons are at risk of osteoarthritis in weight-bearing joints such as the knee, the hips, and feet [9].

To date, literature reviews have given conflicting views based on the available data and method of data retrieval. The purpose of this review is to establish, from recent research, if there is a causal link between obesity and the affliction of low back pain. A secondary purpose of this review is to present the concepts of evidence-based practice to aid the chiropractor or osteopath in looking for health-related evidence for their patients who present with obesity.

\section{Methods}

A MEDLINE search, from the National Library of Medicine, was used to ascertain pertinent articles between the years 1990 and 2004. The use of keywords "obesity", "body mass index", "BMI" and "low back pain" was used to obtain relevant studies. The references of papers retrieved were also reviewed, as were key texts and references.

This section is devoted to presenting the concepts of evidence-based practice (EBP) to demonstrate to the reader the discovery process for finding a possible link between obesity and low back pain. The EBP method used is shown in Table 1.

The first step in this process is "asking an answerable question." In this paper we assume a patient has asked whether being overweight can cause low back pain. Construction of an appropriate answerable question would possibly be "Does an increased BMI cause low back pain?" "Does being overweight create osteoarthritis?" In this way questions can be constructed to allow the practitioner to effectively answer a clinical concern.

Once the answerable question has been constructed the next task is to find an adequate resource. Internet access to the U.S. National Library of Medicine's MEDLINE or
Table I: Steps to asking the answerable question using EBP principles

Step I: Asking an answerable question

Step 2: Selecting an evidence resource

Step 3: Executing the search strategy

Step 4: Examining the evidence summary

Step 5: Application of the evidence

PUBMED, these database systems are considered by many experts to be the most up to date data source on medically related topics. The next step is to determine keywords to place in the search engine. From the answerable question(s) it can be appreciated that the initial keywords will be "low back pain", "BMI" and "osteoarthritis." This search constitutes the third step. In initiating the search, one should look for the search engines "limits" area. In this area can one designate an age group (ex: 45 to 60 years), date span of the literature search, (ex: 1998 to 2003), and to select either English language or articles in foreign languages.

Once the search has been completed, the articles, which may answer the question, are isolated and can be read. Step four involves collating the evidence to answer the question. In searches one may find answers that were not known to exist, and information that may challenge an already preconceived notion. The evidence summary should list the main author and year the paper was published. This is in order to retrieve the data should anyone wish to examine the source. As an example of an evidence summary see Table 2.

It is at this time that the clinician is ready for the final step of applying the evidence. In our example clinical data from the experimental literature may or may not indicate that there is a link between overweight and low back pain.

\section{Results}

The literature search into obesity and joint pain revealed several studies pertinent to the debate. Table 2 reveals an overview of the studies selected. Several studies [4,10-13] had large populations to draw from yet the data from these studies were not in agreement as to a cause or association. In fact, only two studies $[14,15]$ found a direct association for obesity as a risk factor while two $[4,16]$ studies found no association. Several of the studies reviewed were unable to clarify BMI to the satisfaction of the authors.

\section{Discussion}

Interest in the association between obesity and low back pain has piqued researchers interest for many years. Intu- 
Table 2: Recent evidence: Obesity and low back pain (chronological order)

\begin{tabular}{|c|c|c|c|c|}
\hline Author, Year (Ref) & $\mathbf{N}$ & BMI & LBP & Association \\
\hline Melissas, 2003 [14] & 50 & $>40$ & $58 \%$ & direct \\
\hline \multirow[t]{2}{*}{ Bener, 2003 [10] } & 802 & (26.4 males/ 27.8 females) & $56.1 \%$ males & \\
\hline & & & $73.8 \%$ females & moderate \\
\hline Tsuritani, 2002 [16] & 709 & -- & $40.3 \%$ & none \\
\hline Bowerman, 200I [4] & 252 & -- & $29.2 \%$ & none \\
\hline Kostova, 200I [12] & 898 & -- & -- & increased risk \\
\hline Bayramoglu, 200। [15] & 25 & -- & -- & direct \\
\hline \multirow[t]{3}{*}{ Mortimer, 200I [13] } & 475 & $30(43.6 \%)$ & & \\
\hline & & $31-40(28.8 \%)$ & & \\
\hline & & $40+(1.3 \%)$ & -- & increased risk \\
\hline Han, I997 [II] 7018 women & 5887 men NR & -- & & females increased risk \\
\hline
\end{tabular}

$\mathrm{N}=$ number; $\mathrm{BMI}=$ body mass index; $\mathrm{LBP}=$ low back pain; $\mathrm{NR}=$ not reported

Table 3: Clinically relevant differentiation between obesity and overweight

\begin{tabular}{ll}
\hline Overweight & Obesity \\
\hline BMl of 25.0 to $29.9 \mathrm{~kg} / \mathrm{m}^{2}$ & BMl greater than $30 \mathrm{~kg} / \mathrm{m}^{2}$ \\
\hline
\end{tabular}

itively, a burgeoning waistline and an increased lordotic lumbar spine led researchers to conclude that overweight people would be more prone to low back pain. Historically, Kellgren and Lawrence (1958) found that that the prevalence of disk degeneration with obesity was not significant [17]. However, it was not until the mid-1970's when several studies observed a possible association. Obesity was found to increase the prevalence of disk degeneration significantly in a study by Magora and Schwartz in 1976 [18]. Barton et al (1976), in a review of 144 cases, found that $70 \%$ of those who complained of low back pain had been classified as being overweight [19]. This basic research appeared to conclude what was already intuitively thought about low back pain and increased weight.

\section{Body mass index}

Before an in-depth discussion of low back pain and obesity can ensue, the concept of Body Mass Index (BMI) needs to be discussed. BMI is a measure of fatness and is calculated by dividing the patient's weight in kilograms by height in metres squared $\mathrm{kg} / \mathrm{M}^{2}$ [20]. It is widely accepted, easily measured, and predicts morbidity and mortality in many populations [15]. Obesity is generally defined as a BMI of $30 \mathrm{~kg} / \mathrm{m} 2$ and higher $[20,21]$. Overweight is defined as a BMI between 25 and $30 \mathrm{~kg} / \mathrm{m} 2[19,20]$. Overweight tends to be more common in men with obesity being more prevalent among women [21]. When body weight is increased $20 \%$ above average, mortality rises to $20 \%$ for men and $10 \%$ for women [22]. (Table 3) Overweight individuals demand more from their cardio-respiratory and musculoskeletal systems [22]. It is known that more than $50 \%$ of adult Americans have a BMI equal to or greater than 25 [23]. Although there are certain limitations to BMI i.e. large muscular athletes who are in good cardiovascular shape, the rationale behind these numbers is that, across large population groups, there is an increased prevalence of certain diseases in people with a BMI over 25, and a much greater risk of disease and death in those with a BMI over 30 [4]. Being overweight or obese substantially raises the risk of developing hypertension, coronary heart disease, type 2 diabetes, stroke, gallbladder disease, sleep apnea and other respiratory problems, prostate and colon cancers $[4,23]$. Yet, the evidence to date linking it to low back pain is not as clear cut as it is with the previously stated pathologies.

\section{BMI calculation without benefit of BMI charts}

Body Mass Index (BMI) charts and hand held scales are available for individual clinician use. It is, however, unknown to what degree chiropractors or osteopaths use such tools. The following section is designed to aid the clinician with calculating BMI without benefit of chart or hand held scales.

As noted earlier, BMI is calculated as weight in kilograms divided by height in square metres $[20,24]$. This method is often too difficult to calculate for most people. A simpler method for those using the imperial system of measures is to take body weight in pounds $\times 703$ /height in inches squared.

For example, a person weighing 150 pounds at 6 foot tall would correspond to a BMI of 20.3. TABLE 4 
Table 4: Calculation of BMI

$150 \times 703=105450$ divided by 72 inches $(6$ foot $)$ squared. 105450 divided by $5184(72 \times 72)=20.3 \mathrm{BMI}$.

\section{Additional research findings}

Leboeuf-Yde concluded from a review of the literature that due to lack of evidence, body weight should be considered a possible weak risk indicator and suggested that there is insufficient data to assess if it is a true cause of LBP [25]. Kostova found that in men over 40 , overweight, obesity and number of pack years of smoking, estimated by duration of smoking and daily cigarette consumption (more than 20 years and more than 20 cigarettes per day), increased the risk of developing back disorders [12].

Despite these two studies, Garzillo et al and Leboeuf-Yde et al have given conflicting opinions [26,27]. Garzillo's review of the data revealed a possible association between obesity and low back pain only in the upper quintile of obesity, and no evidence of a temporal relationship between weight change and changes in low back pain [26]. Leboeuf-Yde concluded from a twin study that obesity is modestly positively associated with low back pain, in particular with chronic or recurrent low back pain [27].

What appears to be a main concern in linking obesity as a causal factor for low back pain is the numerous variables encountered in these subjects. For example, it is hypothesized that overweight adult females may have negative self-concepts and body images compounded by chronic low back pain and obesity, these may be confounding factors [28]. Other variables such as less activity and/or muscular weakness leading to obesity are also possible considerations.

\section{Obesity and low back pain-related conditions}

Not only is there controversy in obesity and low back pain, but there exists conflicting views of obesity and low back pain-related conditions such as spondylosis, decreased physical activities and discal herniation. The studies demonstrating a positive association are many. O'Neil et al noted that increasing BMI is associated with more frequent findings of osteophytes (bone spurs) at both the thoracic and lumbar spines [29]. The correlation of osteophytes and increased BMI is highest at the thoracic level [29]. Biering-Strenson et al noted absolute weight and BMI are significantly higher in persons 60 years of age with spondylosis [30]. Both men and women with BMI of $30 \mathrm{~kg} / \mathrm{m} 2$ or higher were twice as likely to have difficulties in performing a range of basic daily physical activities [30]. Compared with women with BMI lower than $25 \mathrm{~kg} /$ $\mathrm{m} 2$, those with BMI of $30 \mathrm{~kg} / \mathrm{m} 2$ or higher were 1.5 times
Table 5: BMI-related risk of osteoarthritis and low back pain

\begin{tabular}{ll}
\hline If your BMI is & $\begin{array}{l}\text { then your risk based solely on } \\
\text { BMI }\end{array}$ \\
\hline$<25$ & minimal \\
$25-<27$ & minimal \\
$27-<30$ & minimal \\
$30-<35$ & moderate \\
$35-<40$ & moderate \\
$>40$ & moderate to high \\
\hline
\end{tabular}

more likely to have symptoms of intervertebral disk herniation [31].

Conversely, Luoma et al concluded that disc degeneration is not related to body height, overweight, smoking, or the frequency of physical activity [32]. In addition, studies by Riihimaki, Symmons, and Kang have shown no association between BMI and low back related problems [33-35].

Confounding the data is that the mechanism by which excess body weight causes osteoarthritis is poorly understood [9]. It is believed that contributions from both local increased force across the joint and systemic factors play a role [9]. A discriminating factor between fit and unfit patients with back pain may be the fact that fit persons more frequently are still employed, and as such may be involved more in physical activity [36]. Table 5 indicates where the research currently exists for the link between low back pain and obesity along with obesity and osteoarthritis.

We conclude, based on the available evidence to date, that those individuals with a BMI of under 30 are at a minimal risk of developing low back pain while those persons whose BMI increases to over 30 are a moderate risk of developing low back pain. We also suggest, based on the findings of the Melissas study [14] of those patients who relieved their low back pain symptoms after obesity surgery, that patients with a BMI of greater than 40 are at a high risk of developing low back pain. Albeit controversial, Table 5 may lead to a further refinement of risk of osteoarthritis and low back pain based solely on BMI.

\section{Limitations of obesity as a risk factor for low back pain}

A significant difficulty in ascertaining cause and effect between obesity and low back pain is undoubtedly the term "low back pain" itself. Low back pain is a symptom not a diagnosis. A specific diagnosis, instead of the generalized form of "low back pain" may help separate out the association between LBP and obesity. 
Table 6: Common diagnoses used to explain back symptoms

\begin{tabular}{|c|c|c|}
\hline Annular tear & Adult spondylolysis & Myofascitis \\
\hline Fibromyalgia & Disc syndrome & Strain \\
\hline Spondylosis & Lumbar disc disease & Facet syndrome \\
\hline Degenerative joint disease & Sprain & Spinal OA \\
\hline \multirow[t]{2}{*}{ Disc derangement/disruption } & & Dislocation \\
\hline & $*$ Other potential caus & mology \\
\hline \multicolumn{2}{|l|}{ Failed Back Surgery Syndrome* } & Osteoporosis* \\
\hline \multicolumn{2}{|l|}{ Urinary tract infection* } & Compression fracture* \\
\hline \multicolumn{3}{|c|}{ Somato-visceral mimicry syndrome* } \\
\hline \multicolumn{3}{|c|}{ Organic pathology (tumor, rheumatoid, endometriosis, arthritic disorders)* } \\
\hline \multicolumn{2}{|l|}{ Leg length inequity* } & Sacro-iliac dysfunction* \\
\hline \multicolumn{3}{|l|}{ Hip disorder* } \\
\hline & \multirow{2}{*}{\multicolumn{2}{|c|}{ **Disagreement in research as cause of low back symptomology }} \\
\hline Morbid obesity?** & & \\
\hline
\end{tabular}

$\mathrm{OA}=$ osteoarthritis

The Agency for Health Care Policy and Research (AHCPR) in their 1995 Acute Low Back Problems in Adults noted common diagnoses used to explain back problems [37] (Table $6)$. Given these possible diagnoses one can readily appreciate the dilemma in attempting to link obesity with its specificity in measurement to a broad symptom such as low back pain.

Another problem is the hypothesis that a person who suffers with continuing bouts of low back pain may be predisposed, due to inactivity or inability to exercise, to gain weight thus increasing their BMI. This hypothesis to our knowledge, has yet to be fully discussed and investigated.

\section{Conclusion}

The data for a link between obesity and low back pain appears to be controversial. Yet, this does not adequately address the appropriate therapeutic approach to the obese patient with low back pain. The studies chosen for this review fail to document a definitive causal link between obesity and low back pain. Further research and epidemiologic data is needed to continue the search for a definitive answer.

\section{Competing interests}

The author(s) declare that they have no competing interests.

\section{References}

I. Coulston AM: Obesity as an epidemic: facing the challenge. I Am Diet Assoc 1998, 98( 10 Suppl 2):S6-S8.

2. Zipfel S, Lowe B, Herzog W: Eating behavior, eating disorders, and obesity. Ther Umsch 2000, 57:504-5I0.

3. Lissner L, Steen SN, Brownell KD: Weight reduction diets and health promotion. Am J Prev Med 1992, 8: I54-I 58.

4. Bowerman S, Bellman M, Saltsman P, Garvey D, Pimstone K, Skootsky $\mathrm{S}$, Wang HJ, Elashoff R, Heber D: Implementation of a primary care physician network obesity management program. Obes Res 200I, 9(Supplement 4L):32 IS-325S.
5. Leijon M, Hensing G, Alexanderson K: Sickness absence due to musculoskeletal diagnoses: association with occupational gender segregation. Scand J Public Health 2004, 32:94-101.

6. Skinner HB: Current Diagnosis \& Treatment in Orthopedics Lange Medical Books. New York; 2000.

7. Walker BF, Muller R, Grant WD: Low back pain in Australian adults: the economic burden. Asia Pac J Public Health 2003, 15:79-87.

8. Buckwalter JA, Goldberg VM, Woo SL: Musculoskeletal Soft Tissue Aging: Impact on Mobility American Academy of Orthopedic Surgeons Symposium. Rosemont, IL; 1993.

9. Felson DT: Weight and osteoarthritis. Am J Clin Nutr 1996, 63:430-432.

10. Bener A, Alwash R, Gaber T, Lovasz G: Obesity and low back pain. Coll Antropol 2003, 27:95-104.

II. Han TS, Schouten JS, Lean MEJ, Seidell JC: The prevalence of low back pain and associations with body fatness, fat distribution and height. Int J Obes Relat Metab Disord 1997, 21:600-607.

12. Kostova V, Koleva M: Back disorders (low back pain, cervicobrachial and lumbosacral radicular syndromes) and some related risk factors. J Neurol Sci 200I, 192:17-25.

13. Mortimer M, Wiktorin C, Pernol G, Svensson H, Vingard E, MUSICNorrtalje study group. Musculoskeletal Intervention Center: Sports activities, body weight and smoking in relation to low-back pain: a population-based case-referent study. Scand J Med Sci Sports 200I, I I: 178-84.

14. Melissas J, Volakakis E, Hadjipavlou A: Low back pain in morbidly obese patients and the effect of weight loss following surgery. Obes Surg 2003, 13:389-393.

15. Bayramoglu M, Akman MN, Kilinc S, Cetin N, Yavuz N, Ozker R: Isokinetic measurement of trunk muscle strength in women with chronic low-back pain. Am J Phys Med Rehabil 200 I, 80:650-5.

16. Tsuritani I, Honda R, Noborisaka Y, Ishida M, Ishizaki M, Yamada Y: Impact of obesity on musculoskeletal pain and difficulty of daily movements in Japanese middle-aged women. Maturitas 2002, 42:23-30.

17. Kellgren JH, Lawrence JS: Osteoarthritis and disc degeneration in an urban population. Ann Rheum Dis 1958, 17:388-397.

18. Magora A, Schwartz A: Relation between the low back pain syndrome and x-ray findings. I: Degenerative osteoarthritis. Scand J Rehabil Med 1976, 8: II5-I25.

19. Barton JE, Haight RO, Marsland DW, Temple TE Jr: Low back pain in the primary care setting. J Fam Pract 1976, 3:363-6.

20. Hodge AM, Zimmet PZ: The epidemiology of obesity. Bail Clin Endocrin Metab 1994, 8:577-599.

21. Seidell JC, Flegal KM: Assessing obesity: classification and epidemiology. Brit Med Bull 1997, 53:238-252.

22. Bray GA: Overweight is risking fate: definition, classification, prevalence, and risks. Ann NY Acad Sci 1987, 499: 14-28.

23. Riley RE: Popular weight loss diets. Health and exercise implications. Clin Sports Med 1999, 18:691-70I. 
24. Luoma K, Riihimaki H, Raininko R, Luukkonen R, Lamminen A, Viikari Juntura $E$ : Lumbar disc degeneration in relation to occupation. Scand J Work Environ Health 1998, 24:358-366.

25. Leboeuf-Yde C: Body weight and low back pain. A systematic literature review of 56 journal articles reporting on 65 epidemiologic studies. Spine 2000, 25:226-37.

26. Garzillo MJ, Garzillo TA: Does obesity cause low back pain? J Manipulative Physiol Ther 1994, I 7:60I-4.

27. Leboeuf-Yde C, Kyvik KO, Bruun NH: Low back pain and lifestyle. Part II - Obesity. Information from a population-based sample of 29,424 twin subjects. Spine 1999, 24:779-83.

28. Popkess-Vawter S, Patzel B: Compounded problem: chronic low back pain and overweight in adult females. Orthop Nurs 1992, I I:3 I-5. 43

29. O'Niel TW, McCloskey EV, Kanis JA, Bhalla AK, Reeve J, Reid DM, Todd C, Woolf AD, Silman AJ: The distribution, determinants, and clinical correlates of vertebral osteophytosis: a population based survey. J Rheum 1999, 26:842-848.

30. Biering-Strenson F, Hansen FR, Schroll M, Runeborg O: The relation of spinal $x$-ray to low back pain and physical activity among 60 year old men and women. Spine 1985, 10:445-45I.

31. Lean ME, Han TS, Seidell JC: Impairment of health and quality of life using new US federal guidelines for the identification of obesity. Arch Intern Med 1999, I 59:837-43.

32. Riihimaki H, Wickstrom G, Hanninen K, Luoparjarvi T: Predictors of sciatic pain among concrete reinforcement workers and house painters: a five year follow-up. Scand J Work Environ Health 1989, I 5:415-423.

33. Symmons DP, van Hermert AM, Vandenbroucke JP, Valkenburg HA: A longitudinal study of back pain and radiological changes in the lumbar spine of middle aged women I: clinical findings. Ann Rheum Dis 1991, 50:158-161.

34. Kang SW, Lee WN, Moon JH, Chun SI: Correlation of spinal mobility with the severity of chronic lower back pain. Yonsie Med J 1995, 36:37-44.

35. Verbunt JA, Seelen HA, Vlaeyen JW, van de Heijden GJ, Heuts PH, Pons $\mathrm{K}, \mathrm{Knottnerus} \mathrm{JA:} \mathrm{Disuse} \mathrm{and} \mathrm{deconditioning} \mathrm{in} \mathrm{chronic}$ low back pain: concepts and hypotheses on contributing mechanisms. Eur J Pain 2003, 7:9-21.

36. Bigos SJ, Chair : Acute Low Back Problems in Adults. Clinical Practice Guideline Number 14 Agency for Health Care Policy and Research; 1995.

\section{Publish with Bio Med Central and every scientist can read your work free of charge}

"BioMed Central will be the most significant development for disseminating the results of biomedical research in our lifetime. "

Sir Paul Nurse, Cancer Research UK

Your research papers will be:

- available free of charge to the entire biomedical community

- peer reviewed and published immediately upon acceptance

- cited in PubMed and archived on PubMed Central

- yours - you keep the copyright

Submit your manuscript here:

http://www.biomedcentral.com/info/publishing_adv.asp
BiolMedcentral 